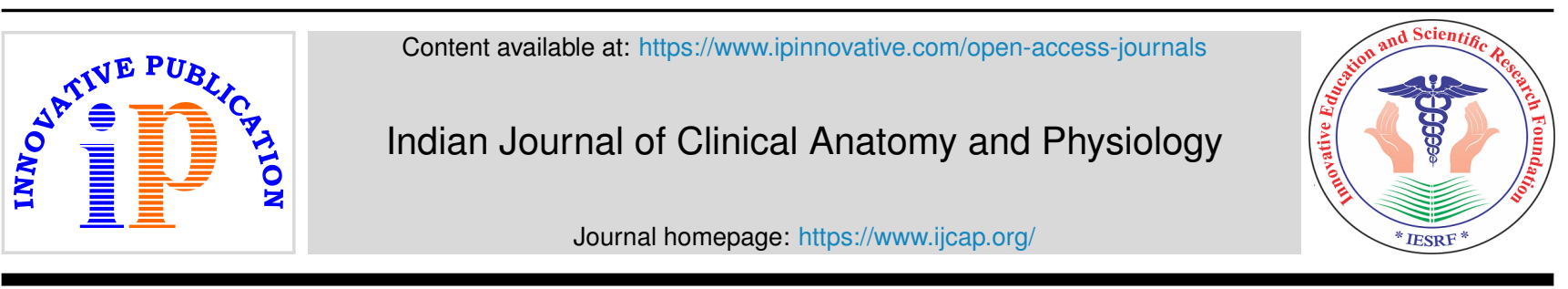

Original Research Article

\title{
Association of blood uric acid with the duration of diabetes in type 2 diabetics: A pilot study
}

\author{
Chandini K ${ }^{1}$, G Manogna ${ }^{2}$, Mohammed Jaffer Pinjar ${ }^{3, *}$ \\ ${ }^{1}$ Dept .of Physiology, GSL Medical College, Rajahmundry, Andhra Pradesh, India \\ ${ }^{2}$ GSL Medical College, Rajahmundry, Andhra Pradesh, India \\ ${ }^{3}$ Dept. of Physiology, Government Medical College, Mahabubanagar, Telangana, India
}

\section{A R T I C L E I N F O}

Article history:

Received 23-11-2020

Accepted 01-12-2020

Available online 11-01-2021

Keywords:

Insulin resistance

Uricase method

\begin{abstract}
A B S T R A C T
Diabetes Mellitus is the most common non-communicable disease which is vastly conquering both the developed \& developing countries of the world. Hypothesis: serum uric acid plays as an independent risk factor for the development of type 2 diabetes. Studies revealing the clearance of uric acid reduced with insulin resistance are few in numbers. A positive correlation between uric acid and glucose levels leads to the development of type 2 diabetes.

Objective: To correlate the levels of blood uric acid with the duration of diabetes in type 2 diabetics.

Materials and Methods: Fifteen type 2 diabetes patients with no history of any complications and other systemic organ \& metabolic disorders like gout \& obesity randomly selected for this cross-sectional study. A biochemical investigation, like the Uricase method employed for fasting serum uric acid levels estimation. Statistical analysis by the Pearson correlation test used.

Results: Positive correlation of serum uric acid with the duration of diabetes in type 2 diabetic patients found to be statistically significant $(r=+0.6, p<0.05)$. Out of fifteen, eleven of them were suffering from hyperuricemia (73\%). Average uric acid level elevated from $6.88 \pm 0.95$ in people with the duration of diabetes 2 to 6 years to $7.61 \pm 3.16$ in people with the duration of diabetes 7 to 10 years.

Conclusion: The positive association of fasting serum uric acid with the duration of type 2 diabetes suggests that uric acid acts as an independent biochemical marker for prognosis of the type 2 diabetes. Drugs that reduce the uric acid levels may be useful in avoiding the development and prognosis of insulin resistance that causes type 2 diabetes and other complications.

(C) This is an open access article distributed under the terms of the Creative Commons Attribution License (https://creativecommons.org/licenses/by/4.0/) which permits unrestricted use, distribution, and reproduction in any medium, provided the original author and source are credited.
\end{abstract}

\section{Introduction}

According to world health organization diabetes is going to be the 7 th leading cause of mortality in 2030. International Diabetes Federation report estimated that 642 million people would be affected by diabetes at the end of the year 2040. Diabetes mellitus is having multiple risk factors and is one of the silent killers of the middle to old aged people in the entire world. It is a metabolic disorder having hyperglycemia associated with dysregulation of lipid and protein metabolism. There are several types of diabetes, out

\footnotetext{
* Corresponding author.

E-mail address: mdjafferkp@gmail.com (M. J. Pinjar).
}

of which type 2 diabetes is because of progressive insulin secretion defect on the background of insulin resistance. In today's scenario, India considered as the diabetes capital of the world. India scores the second-highest number of cases of diabetes in the world after China during the year 2015. ${ }^{1}$ Several independent risk factors are associated with the causation of type 2 diabetes. Among them, prominent risk factors are ageing, increased body mass index, lack of exercise etc. Studies show that elevated uric acid levels in the blood might play as an independent biochemical risk factor for the causation of type 2 diabetes. Uric acid is the end product of the breakdown of purine metabolism. Serum uric acid levels differ as to age increases. In adults, the 
content of uric acid increases steadily and varies with body weight, height, and alcohol intake. ${ }^{2,3}$

Metabolic disorders of purine like gout have a strong positive correlation with insulin resistance that leads to the causation of type 2 diabetes. $^{4}$ Studies have shown that hyperuricemia is associated with the causation of diabetes and obesity. ${ }^{5}$ Bhole $\mathrm{V}$ et al. conducted a prospective study consisted of two generations of the Framingham Heart Study. They concluded that higher levels of serum uric acid were associated with an increased risk of developing type 2DM. Specifically, for every $\mathrm{mg} / \mathrm{dL}$ increase in serum uric acid level, the risk of type $2 \mathrm{DM}$ increased by $20 \%$ in the original cohort $(n=4,883)$ and $15 \%$ in the offspring cohort $(n=4,292)$. These associations persisted in both genders and were independent of other known risk factors of type 2 DM including age, BMI, alcohol consumption, smoking, physical activity level, hypertension, and levels of glucose, cholesterol, creatinine and triglycerides. ${ }^{4}$

Few studies show that reduced clearance of uric acid is associated with hyperinsulinemia that causes insulin resistance in type 2 diabetes. A positive correlation between uric acid and fasting blood glucose levels leads to the causation of type 2 diabetes. Furthermore, certain studies indicate that uric acid functions as pro-oxidant \& antioxidant according to their concentration levels. Blood uric acid has a role of pro-oxidant properties that causes oxidative stress in the cells and results in the resistance of the cells to the insulin. Studies showed hyperuricemia is associated with excess risk for development of type 2 diabetes. ${ }^{6-8}$ Whether the hyperuricemia causes type 2 diabetes, or is it one of the complications of diabetes? Therefore the study is done to know the association of blood uric acid with the duration (2-10 years) of diabetes in people with type 2 diabetes only with no other morbidities and any complications.

\section{Materials and Methods}

\subsection{Study design}

Cross-sectional study.

\subsection{Study setting}

The present study conducted at GSL Medical College, Rajamahendravaram, Andhra Pradesh.

\subsection{Study participants}

Fifty type 2 diabetic patients ( 10 men $\& 5$ women) randomly selected from the medicine outpatient department of GSL hospital for this pilot study. ${ }^{9}$

\subsection{Inclusion criteria}

1. Type 2 diabetics
2. Fasting blood glucose reports within one week $(>110 \mathrm{mg} / \mathrm{dL}$

3. The age group for more than 40 years

4. Both genders included (10 males \& 5 females

5. Duration of diabetes: $2-10$ years

6. BMI: $19-25 \mathrm{Kg} / \mathrm{m} 2$

7. They were taking hypoglycemic drugs regularly or irregularly

8. Willing to participate voluntarily

\subsection{Exclusion criteria}

1. History of CVS, Respiratory, GIT, Renal \& CNS disorders

2. History of endocrine $\&$ metabolic disorders like type 1DM, GOUT

3. Overweight \& obese

4. Smokers

5. Alcoholics

6. Any complications of type 2 diabetes

7. Pregnancy \& lactation

8. Menstrual disorders

Personal, family \& diet history from the patients recorded. General physical examination, height $(\mathrm{cms})$, weight $(\mathrm{kgs})$, BMI $\left(\mathrm{Kg} / \mathrm{m}^{2}\right)$, vitals and systemic examinations performed to rule out the exclusion criteria. Overweight, obese \& hypertensive excluded from the study, which could affect uric acid and insulin resistance in type 2 diabetics. Specific instructions were given to the patients about 8 hour overnight fasting. Collection of the venous blood samples under aseptic precaution at Central Laboratory of the Hospital done. A biochemical investigation like Uricase method (Peroxidase) employed for the estimation of serum uric acid (SUA) levels in the patients. Uricase method: Uric acid in the blood serum utilizes peroxidase system added with several oxygen acceptors to form a chromogen that develops a colour. By using colourimeter absorbance of the intensity measured at 440 nanometer. ${ }^{10}$

\subsection{Ethical considerations}

The study protocol approved by the Institutional ethical committee. Voluntary, written, informed consent taken from the patients before the commencement of the study.

\subsection{Statistical analysis}

Parameters expressed in terms of mean \pm standard deviation. Pearson correlation test used to know the association between SUA \& duration of type 2 diabetes. Statistical SPSS software version 21, Microsoft Word \& Microsoft Excel (Windows 7) employed. 


\section{Results}

Table 1 show the Pearson correlation of SUA with the duration of diabetes in years of type 2 diabetes. The result showed that a positive correlation present between SUA and duration of type 2 diabetes is statistically significant. As the duration of diabetes increases than there is an increase in the serum uric acid concentration in type 2 diabetes patients. SUA in the type 2 diabetes patients was $7.8 \pm 1.7$ (mean $\pm \mathrm{SD})$ stating that they were suffering from hyperuricemia. Hyperuricemia is termed as $>7.0 \mathrm{mg} / \mathrm{dL}$ in males and $>6.0$ $\mathrm{mg} / \mathrm{dL}$ in females. ${ }^{11}$ Out of fifteen, eleven of them were suffering from hyperuricemia (73\%). Average uric acid level elevated from $6.88 \pm 0.95$ in people with the duration of diabetes 2 to 6 years to $7.61 \pm 3.16$ in people with the duration of diabetes 7 to 10 years shown in the Table 2 .

Table 1: Pearson correlation of SUA with the duration of diabetes in Type $2 \mathrm{DM}$ patients

\begin{tabular}{lcc}
\hline Pair & r value & P-value \\
$\begin{array}{l}\text { SUA versus duration of } \\
\text { type 2 diabetes }\end{array}$ & +0.6 & $0.01^{*}$ \\
\hline
\end{tabular}

*statistical significant

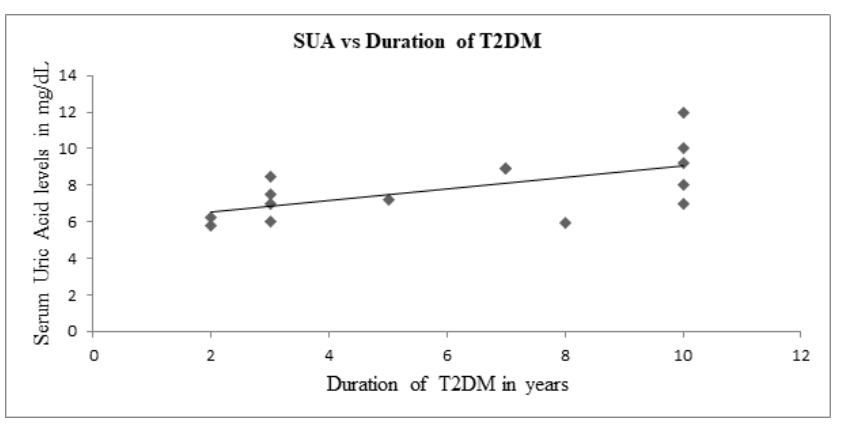

Fig. 1: Pearson correlation between SUA \& duration of type 2 diabetes

Table 2: SUA \& duration of type 2 diabetes (T2DM)

\begin{tabular}{lccc}
\hline Duration of & No. of & \multicolumn{2}{c}{ SUA (mg/dL) } \\
T2DM (years) & $\begin{array}{c}\text { patients (15) } \\
\text { Mean }\end{array}$ & SD \\
$2-6$ & 7 & 6.88 & 0.95 \\
$7-10$ & 8 & 7.61 & 3.16 \\
\hline
\end{tabular}

\section{Discussion}

Blood uric acid acts as an independent risk factor for developing insulin resistance, obesity \& even hypertension showed in the previous literature. A positive correlation between SUA \& the duration of diabetes in type 2 diabetic patients shown in Table 1. Similar results obtained from the study done by Rao TMV \& Vanukuri $\mathrm{NK}^{12}$ on type 2 diabetes patients in India. But in their study exclusion of overweight, obesity \& hypertension not done, which acts as a confounding factor to cause hyperuricemia.

Hyperuricemia can cause dysfunction of endothelial cells and reduced secretion of nitric oxide, that causes insulin resistance \& type 2 diabetes. ${ }^{13}$ Studies done on fructoseinduced hyperuricemia rats leading to insulin resistance \& development of the metabolic syndrome. Hyperuricemia treated by taking hypouricemic drugs. ${ }^{14}$ Some studies showed elevated serum acid levels might cause prediabetes status at the renal level. Hyperinsulinemia with prediabetes can decrease renal excretion of uric acid, as insulin can stimulate the urate-anion exchanger and the sodiumdependent anion co-transporter in brush border membranes of the proximal renal tubule and increase renal urate reabsorption. ${ }^{15-19}$

Strength of the present study: a simple, cost-effective test like uric acid is used, which can guide to diagnose the impaired glucose tolerance leading to insulin resistance. The uric acid level can also guide as a marker of cardiovascular disease, which is the most frequent cause of mortality in diabetes mellitus. The limitations of the present study include small sample size, other biochemical parameters which support the type 2 diabetes-like serum triglycerides, cholesterol, blood urea, serum creatinine, insulin levels, leptin and other inflammatory mediators like $\mathrm{C}$ reactive protein levels not assessed. ${ }^{20}$ The patients were on hypoglycemic drug treatment which could have reduced insulin resistance and hence hyperuricemia.

\section{Conclusions}

The present study has shown a positive correlation existing between SUA \& duration of diabetes in the type 2 diabetics. Further large sample study with other investigations like insulin, leptin levels should be assessed to know the strength of this positive association. From this study, we conclude that by reducing the uric acid levels with medications can help in preventing the occurrence of insulin resistance leading to type 2 diabetes mellitus and its complications.

\section{Conflicts of Interest}

None declared.

\section{Source of Funding}

Nil

\section{Acknowledgements}

We thank the Dean, Principal, HOD of Physiology, GSL Medical College management for allowing conducting the study.

\section{References}

1. International Diabetes Federation. IDF Diabetic Atlas 7th Edition; 2016. Available from: http://www.idf.org/idf-diabetes-atlas-seventh- 
edition. Accessed.

2. Longo D, Fauci A, Kasper D, Hauser S, Jameson JL, Loscalzo J. Disorders of purine and pyrimidine metabolism. In: Wortmann RL, editor. Harrison's Principles of Internal Medicine. New York: McGraw Hill Education; 2012. p. 3181-5.

3. Rodwell VW. Metabolism nucleotides, in Harper's, illustrated biochemistry. et al RM, editor. New York: Mc GrawHill, Lange publishers; 2009

4. Bhole V, Choi JWJ, Kim SW, de Vera M, Choi H. Serum Uric Acid Levels and the Risk of Type 2 Diabetes: A Prospective Study. Am J Med. 2010;123(10):957-61. [oi:10.1016/1.amjmed.2010.03.027.

5. Čaušević A, Semiz S, Macić-Džanković A, Cico B, Dujić T, Malenica M. Relevance of Uric Acid in Progression of Type 2 Diabetes Mellitus. Bosn J Basic Med Sci. 2010;10(1):54-9. dol:10.17305/bjbms.2010.2736.

6. Xu Y, Zhu J, Gao L, Liu Y, Shen J, Shen C. Hyperuricemia as an independent predictor of vascular complications and mortality in type 2 diabetes patients: a meta-analysis. PLoS One. 2013;8(10):78206.

7. Krishnan E, Akhras KS, Sharma H, Marynchenko M, Wu EQ, Tawk $\mathrm{R}$, et al. Relative and attributable diabetes risk associated with hyperuricemia in US veterans with gout. QJM. 2013;106(8):721-9. do1:10.1093/q]med/hct093.

8. Krishnan E, Pandya BJ, Chung L, Hariri A, Dabbous O Hyperuricimeia in young adults \& risk of insulin resistance, prediabetics \& diabetes: A 15 year follow up study. Am J Epidemiol. 2012;176:108-124.

9. Johanson GA, Brooks GP, 2010;70(3):394-400 . Initial Scale Development: Sample Size for Pilot Studies. Educ Psychol Meas. 2010;70(3):394-400.

10. Teitz NW, Brutis CA, Ashwood RE. Fundamentals of Clinical chemistry. 5th ed. New Delhi: Elsevier Publications; 2001.

11. Gagliardi ACM, Miname MH, Santos RD. Uric acid: A marker of increased cardiovascular risk. Atheroscler. 2009;202(1):11-7. doi:10.1016/1.atherosclerosis.2008.05.022

12. Rao T, Vanukuri NK. A study on serum uric acid levels in type 2 diabetes mellitus and its association with cardiovascular risk factors. Int Arch Integr Med. 2016;3(12):148-55.

13. Nakagawa T, Tuttle KR, Short RA, Johnson RJ. Hypothesis: fructoseinduced hyperuricemia as a causal mechanism for the epidemic of the metabolic syndrome. Nat Clin Pract Nephrol. 2005;1(2):80-6. do1:10.1038/ncpnephoorg

14. Hallfrisch J. Metabolic effects of dietary fructose. FASEB $J$ 1990;4(9):2652-60. doi:10.1096/fasebj.4.9.2189777.

15. Maaten JCT, Voorburg A, Heine RJ, Wee PMT, Donker AJM, Gans ROB. Renal Handling of Urate and Sodium during Acute Physiological Hyperinsulinaemia in Healthy Subjects. Clin Sci.

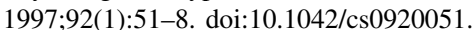

16. Facchini F. Relationship between resistance to insulin-mediated glucose uptake, urinary uric acid clearance, and plasma uric acid concentration. J Am Med Assoc. 1991;266(21):3008-11. doi:10.1001/jama.266.21.3008

17. Muscelli E. Effect of insulin on renal sodium and uric acid handling in essential hypertension. Am J Hypert. 1996;9(8):746-52. ब01:10.1016/0895-7061(96)00098-2

18. Enomoto A, Kimura H, Chairoungdua A. Molecular identification of a renal urate anion exchanger that regulates blood urate levels. Nat. 2002;417(6887):447-52.

19. Choi HK, Mount DB, Reginato AM. Pathogenesis of Gout. Ann Intern Med. 2005;143(7):499-516. 105:10.7326/0003-4819-143-720050040-00000

20. Rao SM. A study of serum uric acid in diabetes mellitus \& prediabetes in a south Indian tertiary care hospital. Nitte Univ J Health Sci. 2012;2(2):18-23

\section{Author biography}

Chandini K, Assistant Professor

G Manogna, MBBS Intern

Mohammed Jaffer Pinjar, Associate Professor

Cite this article: Chandini K, Manogna G, Pinjar MJ. Association of blood uric acid with the duration of diabetes in type 2 diabetics: A pilot study. Indian J Clin Anat Physiol 2020;7(4):334-337. 